\title{
Photo-thermal effect enhances the efficiency of radiotherapy using Arg-Gly-Asp peptides-conjugated gold nanorods that target $\alpha v \beta 3$ in melanoma cancer cells
}

\author{
Ping $\mathrm{Li}^{1,3+}$, Yi-wen Shi ${ }^{2+}$, Bing-xin $\mathrm{Li}^{3}$, Wen-cai Xu${ }^{4}$, Ze-liang Shi ${ }^{3}$, Chuanqing Zhou ${ }^{2^{*}}$ and Shen $\mathrm{Fu}^{1,3^{*}}$
}

\begin{abstract}
Background: Thermotherapy has been known to be one of the most effective adjuvants to radiotherapy (RT) in cancer treatment, but it is not widely implemented clinically due to some limitations, such as, inadequate temperature concentrations to the tumor tissue, nonspecific and non-uniform distribution of heat. So we constructed arginineglycine-aspartate peptides-conjugated gold nanorods (RGD-GNRs) that target the alpha(v) beta(3) Integrin ( $\alpha \vee \beta 3$ ) and investigate whether the photo-thermal effect of RGD-GNRs by near infrared radiation (NIR) could enhance the efficiency of RT in melanoma cancer cells.
\end{abstract}

Results: RGD-GNRs could be seen both on the surface of the cell membranes and cytoplasm of A375 cells with high expression of $\alpha \vee \beta 3$. After exposed to $808 \mathrm{~nm} N I R, R G D-G N R s$ with various concentrations could be rapidly heated up. Compared to other treatments, flow cytometric analysis indicated that RT + NIR + RGD-GNRs increased apoptosis $(p<0.001)$ and decreased the proportion of cells in the more radioresistant $S$ phase $(p=0.014)$. Treated with $\mathrm{NIR}+\mathrm{RGD}-\mathrm{GNRS}$, the radiosensitivity was also significantly enhanced $\left(\mathrm{DMF}_{\mathrm{SF} 2}: 1.41\right)$.

Conclusion: Results of the current study showed the feasibility of using RGD-GNRs for synergetic RT with photothermal therapy. And it would greatly benefit the therapeutic effects of refractory or recurrent malignant cancers.

Keywords: Arg-Gly-Asp peptides, Gold nanorods, Integrin av $\beta 3$, Photo-thermal therapy, Radiotherapy

\section{Background}

Radiotherapy is an effective treatment for numerous cancers. It is estimated that radiotherapy contributes approximately $40 \%$ towards curative treatment of cancer patients [1]. However, radiotherapy is mainly effective to $\mathrm{G} 2 / \mathrm{M}$ phase tumor cells, with little effect to hypoxic cells and $\mathrm{S}$ phase cells, which is the major reasons for recurrence and deadly metastasis after radiotherapy.

\footnotetext{
*Correspondence: zhoucq@sjtu.edu.cn; shen_fu@hotmail.com

${ }^{\dagger}$ Ping Li and Yi-wen Shi contributed equally to this work

1 Department of Radiation Oncology, Shanghai Proton and Heavy lon Center, Fudan University Cancer Hospital, Shanghai, People's Republic of China

${ }^{2}$ School of Biomedical Engineering, Shanghai Jiao Tong University, Shanghai, People's Republic of China

Full list of author information is available at the end of the article
}

Thermotherapy, as a promising approach for killing radioresistant cancer, has been known to be one of the most effective adjuvants to radiotherapy. In addition to direct toxic effect on tumor cells, hyperthermia can kill radioresistant hypoxic cells and $\mathrm{S}$ phase cells [2]. Some preclinical and clinical researchers showed synergetic effects of combining radiotherapy and thermotherapy, especially for refractory or recurrent malignant tumors [3-5]. However, the use of this combined therapy approach has not been adopted in routine clinical practice. This can probably be attributed to the limitations of thermotherapy, such as inadequate temperature concentrations to the deep tumor tissue, nonspecific and non-uniform distribution of heat [6].

To overcome these obstacles, researchers have introduced the use of nanotechnology to thermo-radiotherapy 
[7]. Gold nanorods (GNRs) are ideally suited for photothermal therapy because of their unique optical characteristics $[8,9]$. In particular, when light of wavelength in the visible to near infrared radiation (NIR) region interacts with the particles much smaller than the incident wavelength, the electric field of the light wave induces coherent oscillation of the free electrons locally around the nanoparticle, with a frequency known as the localized surface plasmon resonance frequency [10]. It is easy to tune the longitudinal surface Plasmon resonance (LSPR) wavelengths of GNRs through chemical methods, so that they can match with the center wavelengths of the laser [11]. GNRs of defined size can absorb NIR, leading to the temperature rise over $40{ }^{\circ} \mathrm{C}$. Such temperature is sufficient for sensitizing tumor cells to radiotherapy [12]. Furthermore, GNRs could be used as radiosensitizers due to the high atomic $(\mathrm{Z})$ number elements $(\mathrm{Au})$ [13]. Gold nanoparticles have been shown to cause sensitization with kilovoltage (KV) or Megavoltage (MV) X-ray in vitro and in vivo studies [14, 15]. We have previously shown that GNRs could sensitize melanoma cells to clinically relevant $6 \mathrm{MV} \mathrm{X}$-ray irradiation [15]. Moreover, by conjugating some specific antibodies and peptides, the amount of GNRs accumulated in the tumor site raises greatly, thus enhancing thermal and radio efficacy.

One of such molecular targets is integrins. Overexpression of integrins has been reported in a wide variety of tumors, such as breast cancer, melanoma, and glioblastoma [16]. And it is approved that overexpression of integrins is associated with tumor growth, metastasis and angiogenesis [17]. Among all the integrins, alpha(v) beta(3) Integrin $(\alpha v \beta 3)$ is involved in tumor metastasis, angiogenesis, as well as radiosensitivity. Therefore, targeting $\alpha v \beta 3$ has attracted a great deal of attention due to its role as a potential target for inhibition of angiogenesis and tumor growth. Arginine (R)-glycine (G)-aspartate (D) (RGD) is the most effective and widely used peptide sequence for stimulating cell adhesion on synthetic material surfaces. RGD molecular probes have been developed for selectively binding to $\alpha v \beta 3$. Once the RGD sequence is recognized and bound to integrins, it initiates an integrin-mediated cell adhesion process and activates signal transduction between the cell and extracellular matrix [18].

In this study, we synthesized multifunctional RGD (Arg-Gly-Asp peptides)-conjugated gold nanorods (RGD-GNRs). Such RGD-GNRs could produce significant thermal effect upon $808 \mathrm{~nm}$ NIR and simultaneously serve as radiosensitizers by the high $\mathrm{Z}$ gold. RGD served as a targeting probe to specifically conjugate to tumor cells and we compared the effect of combined treatment of photo-thermal therapy and radiotherapy with either alone. As a result, the combined treatment exhibited a synergistic effect.

\section{Results and discussion \\ Characterization of GNRs}

Before carrying out our studies, we synthesized and characterized the GNRs. The TEM image and measured UV-VIS spectrum are shown in Fig. 1. The length of the GNRs was about $44.4 \mathrm{~nm}$ and the width $15.6 \mathrm{~nm}$ (Fig. 1a, b). As shown in Fig. 1c, the LSPRs of GNRs located at $805 \mathrm{~nm}$. In our nanoconstruct, RGD peptide with high $\alpha \mathrm{v} \beta 3$ binding affinity and low cytotoxicity was conjugated to GNRs through a PEG linker (RGD-GNRs) [15].

\section{RGD mediated specific cell uptake of RGD-GNR}

Next, we evaluated the selectivity of uptaking RGDGNRs in $\alpha \mathrm{v} \beta 3$ positive tumor cells. A375 melanoma cancer cells and MCF-7 breast cancer cells with different expression of $\alpha v \beta 3$ were chosen. Expression of $\alpha v \beta 3$ in these cell lines was investigated by flow cytometry. As shown in Fig. 2a, b, there was a significantly higher expression level of $\alpha \mathrm{v} \beta 3$ in A375 cells but lower expression level of that in MCF-7 cells. Meantime, significantly more RGD-GNRs were internalized in A375 cells than in MCF-7 cells (Fig. 2c, d). These results indicated that cell uptake of RGD-GNRs were mediated by $\alpha v \beta 3$.

\section{Photo-thermal effect caused by GNRs under NIR irradiation}

As is known to all, GNRs exhibit surface plasmon resonance, allowing them to absorb far stronger light in near-infrared area $(650-900 \mathrm{~nm})[8,9]$. Since it is easy to tune the LSPR wavelengths of GNRs, they can match the center wavelength of NIR laser source in photothermal treatment. In this study, the LSPR wavelength of GNR locates at $805 \mathrm{~nm}$. In order to verify the potential of GNRs as the photo-thermal agent, GNRs and RGD-GNRs at different concentrations were exposed to $808 \mathrm{~nm}$ NIR at a power density of $1 \mathrm{~W} / \mathrm{cm}^{2}$ for $15 \mathrm{~min}$. Figure 3 showed the heating curve of GNRs and RGDGNRs at different concentrations. It was shown that after exposure to the NIR, each concentration of GNRs or RGD-GNRs rapidly warmed within $1 \mathrm{~min}$. An obvious concentration-dependent temperature increase was observed either in GNRs or in RGD-GNRs, After $15 \mathrm{~min}$ of continuous NIR irradiation at $1 \mathrm{~W} / \mathrm{cm}^{2}$, the temperature of GNRs or RGD-GNRs group increased about $13^{\circ} \mathrm{C}$ when the concentration was $0.05 \mathrm{mg} / \mathrm{ml}$ and the growth of temperature was of a concentration-dependent manner. As expected, there was no temperature change at all in the groups that did not treated with RGD-GNRs followed by NIR irradiation. The above results well demonstrate the suitability of RGD-GNRs as efficient radiosensitizers and photo-thermal agents. 

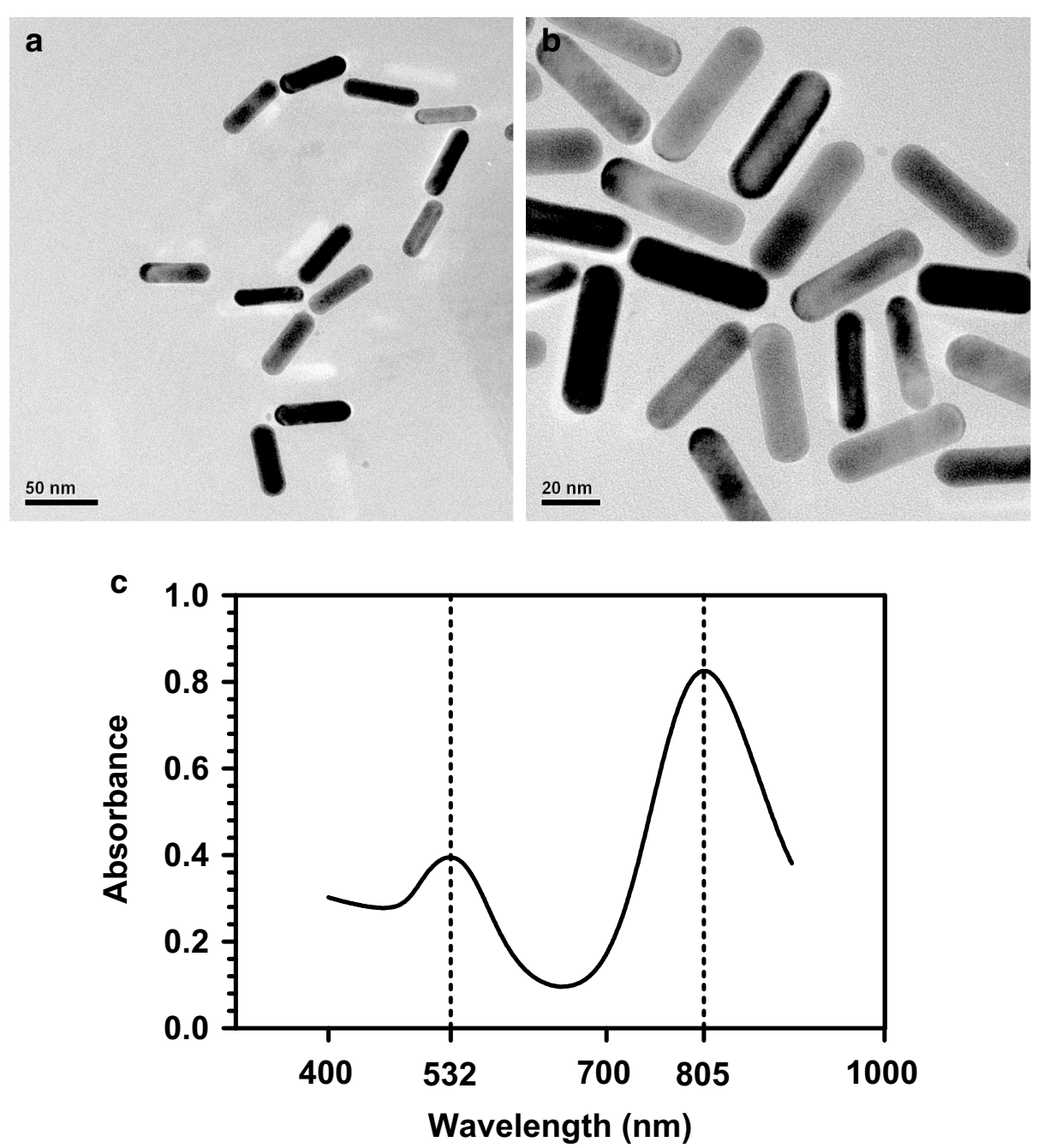

Fig. 1 a The TEM images of GNRs dispersed in PBS. Scale bar $50 \mathrm{~nm}$. b The TEM images ofGNRs dispersed in PBS. Scale bar $20 \mathrm{~nm}$. c Measured UVVIS absorbance spectrum of the synthesized GNRs, showing peak extinction at 805 and $532 \mathrm{~nm}$, respectively.

\section{Photo-thermal effect enhanced radiosensitivity in $\mathrm{A} 375$ cells}

Phase II/III clinical trials have demonstrated that hyperthermia combined with radiotherapy is beneficial for tumor control and survival in patients with radioresistant tumors of different types [4]. Based on the clinical experience, we further assessed the synergistic effect between radiotherapy and photo-thermal therapy. Survival fraction at 2 Gy (SF2) and dose-modifying factor (DMF) values were used to quantify the radiosensitizing effect of the cells. $\mathrm{DMF}_{\mathrm{SF} 2}$ : SF2 (radiation alone)/SF2 (radiation + treatment). We treated the A375 cells with RGD-GNRs by $808 \mathrm{~nm}$ NIR irradiation for $15 \mathrm{~min}$ combined with RT. It was found that treatment of A375 cells with RGD-GNRs resulted in increased radiosensitivity with $\mathrm{DMF}_{\mathrm{SF} 2}=1.288$; however, treatment with NIR was not effective $\left(\mathrm{DMF}_{\mathrm{SF} 2}=1.022\right)$. The radiosensitizing effect was further enhanced by combination treatment with RGD-GNRs and NIR, with a $\mathrm{DMF}_{\mathrm{SF} 2}$ of 1.413 . These results confirmed that RGD-GNRs combined with NIR enhanced the radiosensitizing effect by photo-thermal effect.

\section{Enhanced radiation-induced apoptosis by photo-thermal treatment}

To identify the effect of photo-thermal treatment combined with radiotherapy on apoptosis, we evaluated the apoptosis level based on the flow cytometry. As shown in Fig. 4, NIR or RGD-GNRs alone did not significantly increase the amount of cell apoptosis compared with the control group (NIR vs. Ctr, $p=0.478$; RGD-GNRs vs. Ctr, $p=0.064)$. Radiation alone or combined with NIR 

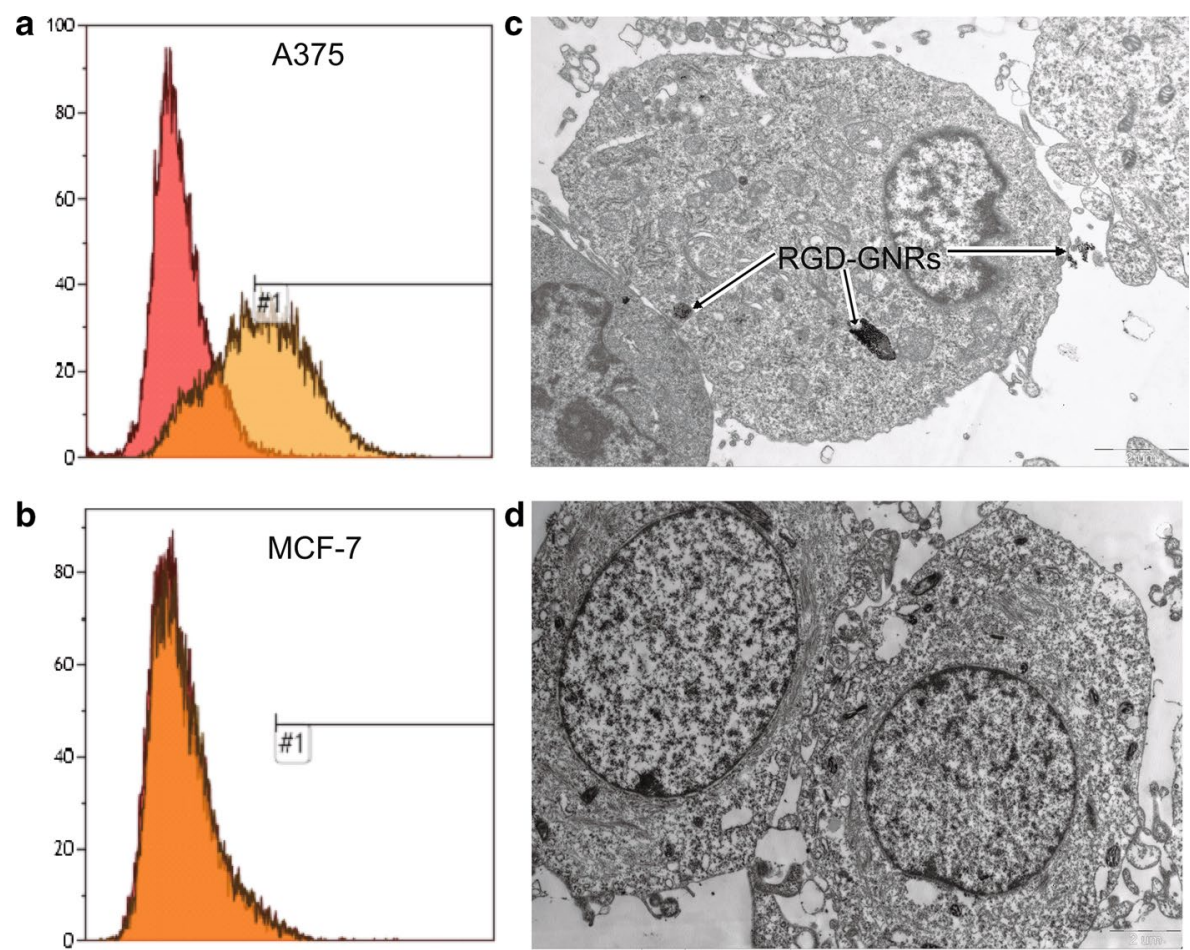

Fig. 2 Cellular uptake of RGD-GNRs. a, b Representative photos of flow cytometry assay of the expression level of $\alpha \mathrm{v} \beta 3$ in A375 and MCF-7 cells. c dTEM analysis of A375 (c) and MCF-7 cells (d) with and without internalized RGD-GNRs.

slightly enhanced apoptosis compared with control group (RT vs. Ctr, $\mathrm{p}=0.007$; RT and NIR vs. Ctr, $p=0.002$ ). The combination of NIR and RGD-GNR with RT resulted in increased apoptosis compared with other treatment groups $(p<0.001)$. Taken together, these data confirmed the synergistic interaction between radiotherapy and photo-thermal treatment.

\section{Decrease the proportion of cells in S phase by photo-thermal treatment}

Considering that hyperthermia-induced radiosensitization is known to be associated with more sensitive to $S$ phase cells, which are resistant to radiation. It was determined whether a cell cycle rationale could be used to account for the greater efficacy of the photo-thermal treatment and radiotherapy combination (Fig. 5). As shown in Fig. 6, after treatment with RGD-GNRs and NIR for $24 \mathrm{~h}$, there were a significant accumulation of cells in $\mathrm{G} 2 / \mathrm{M}$ phase $(p=0.022$, compared with other treatment groups) and a drastic decrease of $\mathrm{S}$ phase cells ( $p=0.014$, compared with other treatment groups), No significant difference can be seen in G0/G1 phase cells among the three groups. So hyperthermia may sensitize cells to radiation by regulating the cell cycle. The combination of thermotherapy and radiotherapy increases damage to all phases of tumor cells, but the killing effects of the S-phase cells are even more markedly enhanced. In addition to directly modulating the cell cycle, thermotherapy can also affect the radiosensitivity in another way. Hyperthermia leads to the denaturation of some proteins, including a variety of DNA-repair enzymes, resulting in irreversible damage [19].

\section{Conclusion}

In summary, we showed that RGD-GNRs significantly enhanced radiosensitivity in A375 cells with high expression of $\alpha v \beta 3$. Moreover, RGD-GNRs showed greater radiosensitizating effect when combined with NIR irradiation then RGD-GNRs alone. The significantly enhanced radiosensitivity of RGD-GNRs could be attributed to: (1) RGDGNRs actively targeted to cancer cells because of high expression of $\alpha \mathrm{v} \beta 3$. (2) Potential effectiveness of GNRs as radiosensitizers for not only $\mathrm{KV}$ X-ray but also MV X-ray. (3) The energy of NIR could be absorbed by RGDGNRs and transferred into local thermal energy, making RGD-GNRs as an ideally candidates for photo-thermal treatment. (4) The synergistic interaction between radiotherapy and thermotherapy. Currently, although extensive preclinical reports are available on the utility of gold nanoparticle for thermally therapeutic applications, there are few reports on using these features to improve the efficacy of radiotherapy. A potential limitation of this combined 

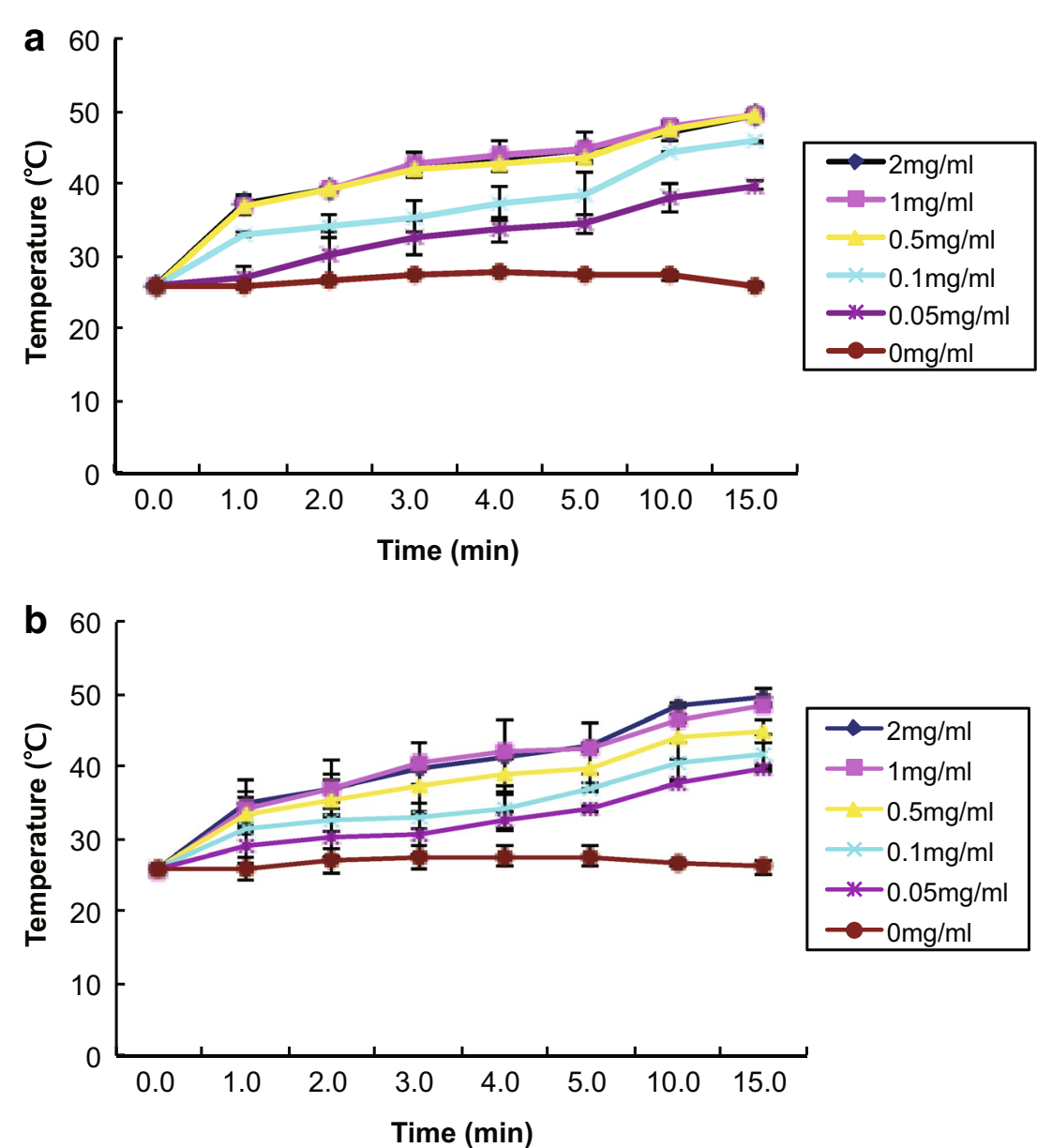

Fig. 3 Heating curve of different concentrations of GNRs (a) and RGD-GNRs (b) $(0,0.05,0.1,0.5,1,2 \mathrm{mg} / \mathrm{ml})$ under $808 \mathrm{~nm}$ NIR at a power density of $1 \mathrm{~W} / \mathrm{cm}^{2}$

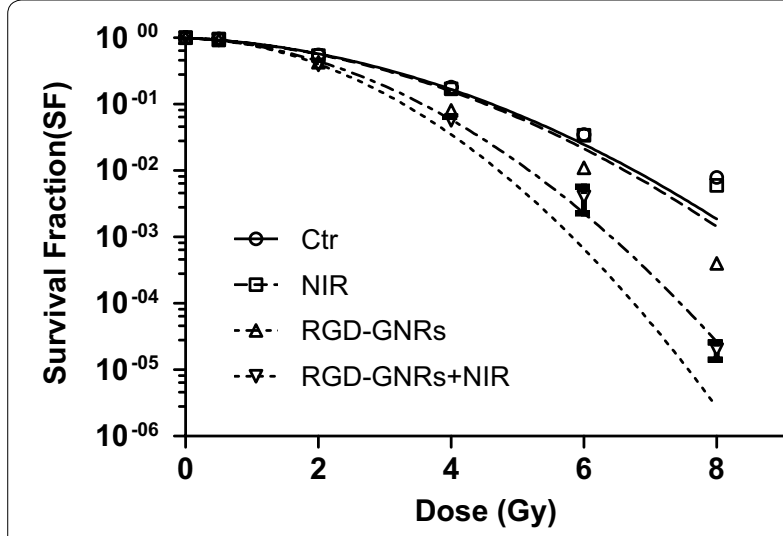

Fig. 4 Radiosensitizing effect by RGD-GNRs and/or NIR. A375 cells were exposed with DMEM (control group), NIR, RGD-GNRs (50 $\mu \mathrm{g} /$ $\mathrm{ml}$ ) or RGD-GNRs + NIR for $1 \mathrm{~h}$, then irradiated at 0-8 Gy with 6MV-X ray. Cells were trypsinized, counted, and seeded at different dilutions. Colonies of 0.50 cells were counted approximately 2 weeks after treatment. radio-photothermal treatment strategy is penetration depth of NIR irradiation. But, melanoma cancer, used in present study, is a superficial radioresistant malignant tumor, which is best suitable for the NIR induced photothermal treatment. To our knowledge, this is the first report that describes use of the RGD conjugated GNRs induced hyperthermia as an adjuvant for radiotherapy to treat melanoma cancer. Our results provide an interesting area for future radio-thermal therapy by some novel materials, such as nanoparticle, because it opens up new possibilities in cancer therapy.

\section{Methods}

\section{Synthesis and characterization of RGD-conjugated gold} nanorods

The gold nanorods were synthesized using the seedmediated template-assisted protocol [20] by reducing gold salt in the presence of surfactant-directed synthesis. 


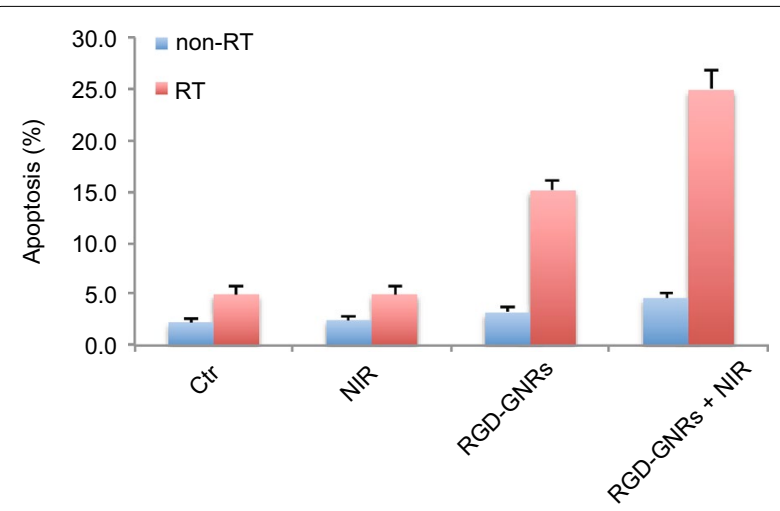

Fig. 5 The apoptosis of the A375 cells after NIR or/and RGD-GNRs treatment. A375 cells were treated with RGD-GNRs or/and irradiation for $1 \mathrm{~h}$ prior to irradiation ( $6 \mathrm{mV}$ X-rays with a dose of $4 \mathrm{~Gy}$ ). The cells were stained with Annexin $V$ and propidium iodide, and apoptosis was analyzed by flow cytometry after $24 \mathrm{~h}$ of treatment.

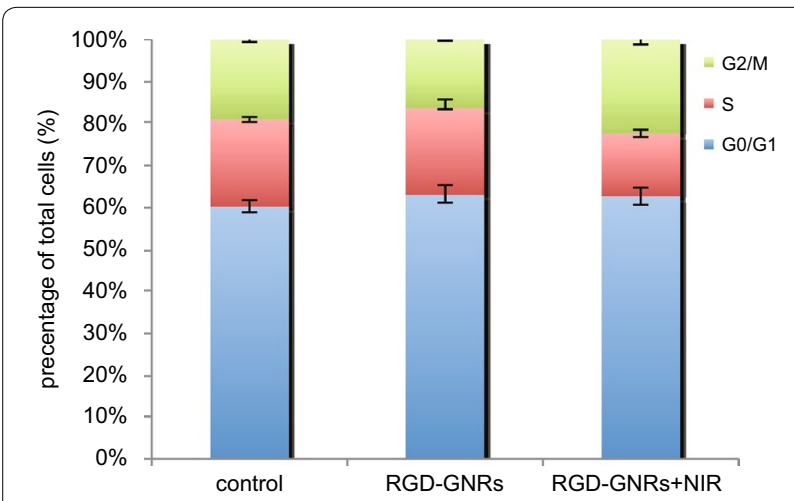

Fig. 6 The changes in cell cycle distribution by treatment of RGDGNRs and NIR in A375 cells. A375 cells were incubated with 0.05 mg/ $\mathrm{ml}$ RGD-GNRs, then the cells were or were not irradiated with $808 \mathrm{~nm}$ NIR with the power density of $1 \mathrm{~W} / \mathrm{cm}^{2}$ for $1 \mathrm{~h}$. After $24 \mathrm{~h}$, the cells were analyzed by flow cytometry.

The seed solution was produced by the reduction of chlorozuric acid ( $5 \mathrm{ml}, 0.5 \mathrm{mmol}$ ) with ice-cold $\mathrm{NaBH} 4$ $(0.6 \mathrm{ml}, 10 \mathrm{mmol})$ in the presence of CTAB $(5 \mathrm{ml}$, $0.2 \mathrm{~mol}$ ) solution (Sinopharm Chemical Reagent Co., Ltd. Shanghai, China). For the growth solution, $100 \mathrm{ml}$ of

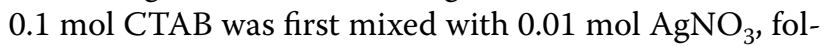
lowed by $0.01 \mathrm{~mol}$ chloroauric acid, $0.1 \mathrm{~mol} \mathrm{AA}, 0.5 \mathrm{~mol}$ $\mathrm{H}_{2} \mathrm{SO}_{4}$, and $250 \mu \mathrm{l}$ of seed solution. Finally, the resulting solution was incubated at $30^{\circ} \mathrm{C}$ over a period of $20 \mathrm{~h}$. The procedure of preparing RGD conjugated GNRs is introduced as follows. First, the as-prepared GNRs solution was centrifuged twice at 9,600 rpm for $25 \mathrm{~min}$. Then, a stock solution of SH-PEG-COOH $(10 \mathrm{mg} / \mathrm{ml}$ ) (Shanghai Yare Biotech, Inc. Shanghai, China) was added into a freshly prepared GNR solution under vigorous stirring for $2 \mathrm{~h}$. All the GNRs samples were centrifuged twice and redispersed in deionized water. The RGD peptides (China Peptides Co., Ltd. Shanghai, China) were covalently attached to the outer ends of the PEG-GNRs via amide bonds, using the standard EDC-NHS reaction [21]. A solution of RGD in deionized water was added to a volume of PEGylated gold nanorods to react for $3 \mathrm{~h}$ and excess RGD peptides were removed by centrifugation at 10,000 rpm for $10 \mathrm{~min}$. The RGD-GNRs were dispersed in Dulbecco's Modified Eagle Medium (Hyclone, Carlsbad, CA, USA) and stored at $4{ }^{\circ} \mathrm{C}$ for later cell experiments. GNRs samples were analyzed with a transmission electron microscopy (TEM) (JEM-2010HT, JEOL, Japan) operating at an accelerating voltage of $200 \mathrm{kV}$. UV-VIS absorbance spectra were measured with a UV-VIS spectrophotometer (Cary-100, Agilent, America) in the wavelength range from 400 to $900 \mathrm{~nm}$.

\section{Cell lines and culture}

Human melanoma A375 cells with high expression of $\alpha v \beta 3$ and human breast cancer MCF-7 cells with low expression of $\alpha \mathrm{v} \beta 3$ were purchased from the Shanghai Institute of Cell Biology and Chinese Academy of Sciences (Shanghai, China) and grown in $5 \% \mathrm{CO}_{2}$ incubator at $37{ }^{\circ} \mathrm{C}$ using Dulbecco's Modified Eagle Medium (DMEM) with $10 \%$ fetal bovine serum (Hyclone).

\section{Integrin $\alpha v \beta 3$ analysis}

A375 and MCF-7 cells were collected and suspended in phosphate- buffered saline $/ 0.2 \%$ bovine serum albumin. A $200 \mu \mathrm{l}$ sample of the suspension was incubated with a mouse antihuman integrin $\alpha \mathrm{v} \beta 3$ mAb LM609 (Millipore, Shanghai, China) or isotype-matched control antibody DD7 (Millipore) for $45 \mathrm{~min}$ at $4{ }^{\circ} \mathrm{C}$. The cells were washed three times with phosphate-buffered saline and analyzed using a flow cytometry (Becton-Dickinson, Frank- lin Lakes, NJ, USA).

\section{TEM analysis of cells with internalized gold nanorods}

A375 and MCF-7 cells previously incubated with RGDGNRs were washed three times with phosphate-buffered saline and fixed with $2.5 \%$ glutaraldehyde for $6 \mathrm{~h}$. The cells were post-fixed in $1 \%$ osmium tetroxide for $2 \mathrm{~h}$, dehydrated in ethanol, and embedded in agar resin (Agar Scientific, Stansted, Essex, UK). Thin Sects. (60-70 nm) were collected on copper grids, stained with methanol and lead citrate, and analyzed with a analyzed with a TEM (JEM-2010HT, JEOL, Japan) operating at an accelerating voltage of $200 \mathrm{kV}$.

\section{Measurements of heating GNRs and RGD-GNRs by near-infrared radiation}

The photo-thermal properties of gold nanorods were examined using a high-power NIR laser source. Laser 
irradiation was accomplished using an Connet Highly Stabilized Laser Source System (VLSM-808-B-070), with a wavelength of $808 \mathrm{~nm}$ at a power density of $1 \mathrm{~W} / \mathrm{cm} 2$ and a spot size of $5 \mathrm{~mm}$ diameter. The GNRs or RGDGNRs were diluted in DMEM with various concentrations. After ultrasonic dispersion, a $500 \mu \mathrm{l}$ volume of gold nanorods with different concentrations were put into $600 \mu \mathrm{l}$ EP tubes. Subsequently, these samples were irradiated with an NIR laser for $15 \mathrm{~min}$. Meanwhile, the temperature was measured and the heating curves were drawn.

\section{Clonogenic assay}

Exponentially growing cells were exposed with DMEM (control group), NIR, RGD-GNRs $(50 \mu \mathrm{g} / \mathrm{ml})$ or RGDGNRs + NIR for $1 \mathrm{~h}$, then irradiated at 0-8 Gy with $6 \mathrm{MV}-\mathrm{X}$ ray. After $48 \mathrm{~h}$, the cells were detached, counted, and seeded at different dilutions according to the irradiation dose and grown for 2 weeks to form colonies. The colonies were stained with $0.4 \%$ crystal violet. Only colonies containing $\geq 50$ cells were scored. All experiments were repeated three times. Survival curves were fitted to a linear quadratic (LQ) model using Graphpad Prism software (version 5.0).

\section{Cell cycle and apoptosis assays by flow cytometry}

A375 cells $\left(10^{6}\right.$ cells $\left./ \mathrm{ml}\right)$ fixed in $95 \%$ ethanol at $-20{ }^{\circ} \mathrm{C}$ for $24 \mathrm{~h}$ were washed with cold phosphate-buffered saline, resuspended, and stained with propidium iodide $(50 \mu \mathrm{g} / \mathrm{ml}$ phosphate-buffered saline; Invitrogen, Shanghai, China) for $15 \mathrm{~min}$ at $4{ }^{\circ} \mathrm{C}$. Analysis was performed using a FACS Calibur flow cytometry. Cellular DNA content and cell cycle data were analyzed by flow cytometry using multicycle system 2.0 software. For the apoptosis assay, the cells were stained with Annexin-V-fluorescein isothiocyanate/propidium iodide (Invitrogen) and measured by flow cytometry. All tests were repeated three times.

\section{Statistical analysis}

All the experiments were completed in three triplicates, Statistical analysis was performed using Student's t test, and $\mathrm{p}$ value was calculated based on two-tailed test. $\mathrm{p}<0.05$ was considered statistically significant. SPSS 11.0 software was used for all statistical analyses.

\footnotetext{
Abbreviations

RGD: arginine (R)-glycine (G)-aspartate (D); GNRs: gold nanorods; RT: radiotherapy; NIR: near infrared radiation; RGD-GNRs: arginine-glycine-aspartate peptides-conjugated gold nanorods; Ctr: control; LSPR: localized surface plasmon resonance; KV: kilovoltage; MV: Megavoltage; TEM: transmission electron microscopy; $\alpha \vee \beta 3$ : alpha(v) beta(3) Integrin; $\mathrm{DMF}_{\mathrm{SF} 2}$ : DMF = dosemodified factor, SF2 = survival fraction at 2 Gy; DMEM: Dulbecco modified Eagle medium.
}

\section{Authors' contributions}

PL carried out the biology assay, performed the statistical analysis and drafted the manuscript; YS performed the preparation and characteristics of RGDGNRs and co-drafted the manuscript. SF and CZ participated in the designed the study and supervised the whole work. BL, WX and ZS helped with the biological study. All authors read and approved the final manuscript.

\section{Author details}

${ }^{1}$ Department of Radiation Oncology, Shanghai Proton and Heavy lon Center, Fudan University Cancer Hospital, Shanghai, People's Republic of China. ${ }^{2}$ School of Biomedical Engineering, Shanghai Jiao Tong University, Shanghai, People's Republic of China. ${ }^{3}$ Department of Radiation Oncology, 6th People's Hospital of Jiao Tong University, Shanghai, People's Republic of China. ${ }^{4}$ Department of Radiation Oncology, Zhengzhou University He'nan Cancer Center, Zhengzhou, He'nan, People's Republic of China.

\section{Acknowledgements}

This article is funded by the research grant (YG2012ZD02, 2JC1407400) from Shanghai Jiao Tong University and the Science and Technology Commission of Shanghai, China and the grant $(81301926,81272506,61227017)$ from National Natural Science Foundation of China.

\section{Compliance with ethical guidelines}

\section{Competing interests}

The authors declare that they have no competing interests.

Received: 14 April 2015 Accepted: 3 August 2015

Published online: 28 August 2015

\section{References}

1. Barnett GC, West CM, Dunning AM, Elliott RM, Coles CE, Pharoah PD et al (2009) Normal tissue reactions to radiotherapy: towards tailoring treatment dose by genotype. Nat Rev Cancer 9:134-142

2. Rao W, Deng ZS, Liu J (2010) A review of hyperthermia combined with radiotherapy/chemotherapy on malignant tumors. Crit Rev Biomed Eng 38:101-116

3. Wessalowski R, Schneider DT, Mils O, Friemann V, Kyrillopoulou O, Schaper J et al (2013) Regional deep hyperthermia for salvage treatment of children and adolescents with refractory or recurrent non-testicular malignant germ-cell tumours: an open-label, non-randomised, singleinstitution, phase 2 study. Lancet Oncol 14:843-852

4. Franckena M, Lutgens LC, Koper PC, Kleynen CE, van der Steen-Banasik EM, Jobsen JJ et al (2009) Radiotherapy and hyperthermia for treatment of primary locally advanced cervix cancer: results in 378 patients. Int J Radiat Oncol Biol Phys 73:242-250

5. Linthorst M, van Geel AN, Baaijens M, Ameziane A, Ghidey W, van Rhoon GC et al (2013) Re-irradiation and hyperthermia after surgery for recurrent breast cancer. Radiother Oncol 109:188-193

6. Horsman MR, Overgaard J (2007) Hyperthermia: a potent enhancer of radiotherapy. Clin Oncol (R Coll Radiol) 19:418-426

7. Bakht MK, Sadeghi M, Pourbaghi-Masouleh M, Tenreiro C (2012) Scope of nanotechnology-based radiation therapy and thermotherapy methods in cancer treatment. Curr Cancer Drug Targets 12:998-1015

8. Mackey MA, Ali MR, Austin LA, Near RD, El-Sayed MA (2014) The most effective gold nanorod size for plasmonic photothermal therapy: theory and in vitro experiments. J Phys Chem B 118:1319-1326

9. Wang J, Dong B, Chen B, Jiang Z, Song H (2012) Selective photothermal therapy for breast cancer with targeting peptide modified gold nanorods. Dalton Trans 41:11134-11144

10. Mannelli I, Marco MP (2010) Recent advances in analytical and bioanalysis applications of noble metal nanorods. Anal Bioanal Chem 39:2451-2469

11. Huang X, El-Sayed IH, Qian W, El-Sayed MA (2006) Cancer cell imaging and photothermal therapy in the near-infrared region by using gold nanorods. J Am Chem Soc 128:2115-2120

12. Lal S, Clare SE, Halas NJ (2008) Nanoshell-enabled photothermal cancer therapy: impending clinical impact. Acc Chem Res 41:1842-1851 
13. Ngwa W, Kumar R, Sridhar S, Korideck H, Zygmanski P, Cormack RA et al (2014) Targeted radiotherapy with gold nanoparticles: current status and future perspectives. Nanomed (Lond) 9:1063-1082

14. Chattopadhyay N, Cai Z, Kwon YL, Lechtman E, Pignol JP, Reilly RM (2013) Molecularly targeted gold nanoparticles enhance the radiation response of breast cancer cells and tumor xenografts to X-radiation. Breast Cancer Res Treat 137:81-91

15. Xu W, Luo T, Li P, Zhou C, Cui D, Pang B et al (2012) The radiosensitization of melanoma cells by gold nanorods irradiated with MV X-ray. Nano Biomed Eng 4:6-11

16. Hood JD, Cheresh DA (2002) Role of integrins in cell invasion and migration. Nat Rev Cancer 2:91-100

17. Hodivala-Dilke K (2008) Alphavbeta3 integrin and angiogenesis: a moody integrin in a changing environment. Curr Opin Cell Biol 2:514-519
18. Makrilia N, Kollias A, Manolopoulos L, Syrigos K (2009) Cell adhesion molecules: role and clinical significance in cancer. Cancer Invest 27:1023-1037

19. Takahashi A, Matsumoto H, Nagayama K, Kitano M, Hirose S, Tanaka H et al (2004) Evidence for the involvement of double-strand breaks in heat-induced cell killing. Cancer Res 64:8839-8845

20. Pan B, Ao L, Gao F, Tian H, He R, Cui D et al (2005) End-to-end self-assembly and colorimetric characterization of gold nanorods and nanospheres via oligonucleotide hybridization. Nanotechnology 16:1776-1780

21. Johnsson B, Löfås S, Lindquist G (1991) Immobilization of proteins to a carbosymethyldextran-modified gold surface for biospecific interaction analysis in surface Plasmon resonance sensors. Anal Biochem 198:268-277
Submit your next manuscript to BioMed Central and take full advantage of:

- Convenient online submission

- Thorough peer review

- No space constraints or color figure charges

- Immediate publication on acceptance

- Inclusion in PubMed, CAS, Scopus and Google Scholar

- Research which is freely available for redistribution

Submit your manuscript at www.biomedcentral.com/submit 